\title{
Blood loss of total knee arthroplasty in osteoarthritis: an analysis of influential factors
}

\author{
Yong Hu', Qiang Li $i^{1,2}$, Bao-Gang Wei ${ }^{1,3}$, Xian-Sen Zhang ${ }^{1,4}$, Tahsin Tarik Torsha ${ }^{5}$, Jun Xiao ${ }^{1 *}$ (D and Zhan-Jun Shi
}

\begin{abstract}
Background: Total knee arthroplasty is regarded as the most effective treatment for severe knee osteoarthritis. The influential factors of blood loss in total knee arthroplasty remain controversial. The study aims to explore the influential factors of blood loss in total knee arthroplasty comprehensively.

Material and methods: Three hundred and four osteoarthritis patients undergoing unilateral primary total knee arthroplasty were enrolled. Demographic characteristics, laboratory results, surgical protocol, and hemostatic and anticoagulation drugs were collected. Estimation of blood loss was calculated using the Gross equation. Multivariable stepwise linear regression analysis was performed to find out the influential factors.

Results: Total blood loss reached the biggest volume $(1346 \pm 671 \mathrm{~mL})$ in the post-operative third day. Hidden blood loss reached $465 \pm 358 \mathrm{~mL}$. Gender, tranexamic acid, prosthesis type, and drainage were proven to be positively correlated with the total blood loss (all $P<0.05$ ). Male appeared to suffer more surgical blood loss than female. Posterior cruciate stabilizing prosthesis might lead to more surgical blood loss than posterior cruciate retaining prosthesis. Tranexamic acid could effectively reduce total blood loss while drainage might increase bleeding. Gender and anticoagulation drugs were correlated with hidden blood loss (both $P<0.05$ ). Low molecular weight heparin resulted in less hidden blood loss than rivaroxaban.

Conclusions: Posterior cruciate retaining prosthesis and topical use of tranexamic acid were preferred to reduce total blood loss. Drainage was not recommended due to the risk of increasing bleeding. Low molecular weight heparin was recommended to prevent venous thrombosis.
\end{abstract}

Keywords: Total knee arthroplasty, Blood loss, Influential factor

\section{Background}

Symptomatic knee osteoarthritis (OA) is highly prevalent amongst older people worldwide, and the morbidity even reached $30 \%$, especially in rural regions [1]. Total knee arthroplasty (TKA) is regarded as the most effective treatment for severe knee OA, with rates of excellent or good long-term outcomes reaching 98\% [2-4]. Despite significant improvement in surgical techniques [5], the large blood loss after TKA remains a concern of surgeons. The total blood loss even reached $1500 \mathrm{~mL}$ in average [5-8], which also led to high transfusion rate.

\footnotetext{
* Correspondence: orthopaedxi@163.com

'Department of Orthopaedic Surgery, Nanfang Hospital, Southern Medical

University, Guangzhou 510515, Guangdong Province, China

Full list of author information is available at the end of the article
}

Up to $70 \%$ of patients who undergo total joint arthroplasty received blood transfusion [9]. Allogeneic blood transfusion might increase the risk of longer hospital stays, infectious disease transmission, immunologic reactions, hemolytic and anaphylactic reactions, and increased mortality [10].

Identifying influential factors of surgical blood loss is an important step toward establishing an effective blood management strategy and further reducing the need for perioperative blood transfusion. However, the existing results of influential factors in OA patients undergoing TKA remain controversial. Cushner and Friedman found that gender of the patients was positively related to blood loss, but excluded the correlation of age, diagnosis, and operative time [11]. Another research conducted

(C) The Author(s). 2018 Open Access This article is distributed under the terms of the Creative Commons Attribution 4.0 International License (http://creativecommons.org/licenses/by/4.0/), which permits unrestricted use, distribution, and 
by Lošták et al. proposed different opinion, and they declared that the characteristics affecting the amount of blood loss in TKA were BMI, preoperative platelet count, and INR [7]. Mesa-Ramos et al. denied the correlation between age, sex, BMI, and blood loss in TKA [12]. Tranexamic acid (TXA) [8, 13], tourniquet [14], and anticoagulation drugs [15] were also proven to be positively associated with blood loss in TKA. But some potential risk factors, such as coagulation system, electrolyte disturbance, prosthesis type, and material of plugging the femoral hole, are lack of further study.

In the present study, 304 cases undergoing unilateral TKA in our department from the year 2011 to 2016 were enrolled in the study. Excluding from the influence of diagnosis, we only included patients diagnosed as having knee osteoarthritis. Gross equation was adopted to estimate the volume of surgical blood loss. Multivariable stepwise linear regression analysis was performed to explore the influential factors, in which we included as many risk factors as possible. The potential risk factors include gender, BMI, coagulation indexes, electrolyte, surgical protocol, and hemostatic and anticoagulation drugs. The study aims to comprehensively explore the exact factors influencing blood loss in total knee arthroplasty surgery.

\section{Methods}

\section{Patients}

Patients who were diagnosed with knee $\mathrm{OA}$ and underwent unilateral TKA from January 2011 to June 2016 were included in the study. Those with the following conditions were excluded, including rheumatoid arthritis, ankylosing spondylitis, Kashin Beck disease, active infection, tumor, severe cerebrovascular disease, liver disease with severe abnormal liver function, and hematologic diseases like coagulation dysfunction (such as hemophilia) and thrombocytopenia. In addition, patients with long-term use of anticoagulant drugs were also excluded. For hypertensive patients, the preoperative blood pressure was controlled to beneath 140/90 $\mathrm{mmHg}$.

Finally, 304 patients consisting of 61 males and $243 \mathrm{fe}-$ males were included in the study. The average age was 56.8 years, ranging from 42 to 80 . The average BMI was $26.46 \mathrm{~kg} / \mathrm{m}^{2}$, which was defined as overweight. The different protocol of the patients was described in Table 1, and the laboratory test results were shown in Table 2.

\section{Surgical indication, technique, and perioperative management}

Severe pain affecting daily activity, dysfunction of joint motion, and radiography evidence that narrowing joint space with cystic change of subchondral bone, bone sclerosis and formation of osteophyma, were the main
Table 1 Patients' characters

\begin{tabular}{lll}
\hline & Variables & Value \\
\hline Gender & Male & 61 \\
& Female & 243 \\
Prosthesis type & Posterior cruciate stabilizing & 204 \\
& Posterior cruciate retaining & 100 \\
Anticoagulation & Low molecular weight heparin & 129 \\
& Rivaroxaban & 175 \\
Hemocoagulase & Non-utilization & 37 \\
agkistrodon & Utilization & 267 \\
Material of filling the & Nothing & 124 \\
location hole of femurs & Cement & 98 \\
& Bone & 82 \\
Use of TXA & Topical application & 63 \\
& Combined application & 54 \\
& Non-application & 122 \\
Drainage & Intravenous application & 65 \\
& Non-utilization & 202 \\
& Utilization & 102 \\
\hline
\end{tabular}

indications for OA patients to receive TKA after invalid conservative treatment.

Standard surgical methods were adopted for all patients (median knee incision, with incision length ranging from 10 to $15 \mathrm{~cm}$ ), and all the surgeries were performed in the supine position by the same experienced team. General anesthesia or spinal anesthesia was performed. Tourniquet was commonly used during the operation, and the pressure was set in $60 \mathrm{kPa}$. Cephalosporins were routinely applied for $24 \mathrm{~h}$ after operation to

Table 2 Assessment of the patients

\begin{tabular}{|c|c|}
\hline & Mean \pm SD \\
\hline $\mathrm{BMI}\left(\mathrm{kg} / \mathrm{m}^{2}\right)$ & $26.46 \pm 3.495$ \\
\hline Preoperative APTT (s) & $28.87 \pm 4.378$ \\
\hline Preoperative Fbgc (g/L) & $3.24 \pm 1.058$ \\
\hline Preoperative Hct & $0.39 \pm 0.037$ \\
\hline Preoperative kalium (mmol/L) & $4.02 \pm 0.331$ \\
\hline Preoperative calcium (mmol/L) & $3.19 \pm 9.98$ \\
\hline Preoperative magnesium (mmol/L) & $0.88 \pm 0.110$ \\
\hline Operation time (min) & $109.72 \pm 25.88$ \\
\hline Preoperative PT (s) & $11.49 \pm 1.144$ \\
\hline Preoperative $\Pi \mathrm{T}(\mathrm{s})$ & $17.41 \pm 1.896$ \\
\hline Preoperative $\mathrm{Hb}(\mathrm{g} / \mathrm{L})$ & $12.797 \pm 1.4347$ \\
\hline Preoperative ALB (g/L) & $38.91 \pm 3.688$ \\
\hline Preoperative natrium (mmol/L) & $141.87 \pm 2.941$ \\
\hline Preoperative phosphorus (mmol/L) & $1.20 \pm 0.177$ \\
\hline Age (years) & $66.15 \pm 7.58$ \\
\hline
\end{tabular}


prevent infection. Two kinds of prostheses included posterior cruciate retaining (CR) prosthesis and posterior cruciate stabilizing (PS) prosthesis. The material of plugging the location hole of femur included cement and bone. Autologous re-transfusion drainage regimen was applied in the study, which had beneficial effects of higher post-operative hemoglobin and lower allogenic transfusion rate $[16,17]$. The drainage tube was located in the proximal lateral incision into the joint cavity, which was connected to an autologous re-transfusion drainage device (ConstaVac TM CBC II, Stryker, USA) that worked under the minimum level of negative pressure. The reinfusion process was completed within $6 \mathrm{~h}$ from the beginning of collecting drainage blood for each case. Tranexamic acid (TXA) with different usage method was applied, which included topical use, intravenous use, and combined use. Hemocoagulase agkistrodon (HCA) was also applied for reducing bleeding in some cases. Low molecular weight heparin (LMWH) or rivaroxaban was used in $12 \mathrm{~h}$ post-operatively to prevent deep venous thrombosis (DVT).

Physical exercise and continuous passive motion exercise device (CPM) were applied on post-operative day 1 until discharge. Physical exercises were performed twice daily according to standard guidelines [18, 19], including isometric quadriceps exercise, active knee flexion and extension exercise, ankle pump exercise, and straight leg raising exercise. Referring to the studies of Pope et al. [19] and Goletz et al. [20], all patients received CPM with an initial range of 0 to $40^{\circ}$ and 10 to $15^{\circ}$ of increments daily. All patients received three CPM sessions per day (each lasting $2 \mathrm{~h}$ ) in a supine position with the head of the bed 30 to $60^{\circ}$ angle of inclination [21].

\section{Collecting data}

Age, sex, height, and weight were recorded. Both preoperative hemoglobin $(\mathrm{Hb})$ and hematocrit $(\mathrm{Hct})$ and post-operative results in the first, third, and fifth days after operation were collected. Preoperative laboratory test results including prothrombin time (PT), activated partial thromboplastin time (APTT), thrombin time (TT), fibrinogen concentration (Fbgc), albumin (ALB), kalium, natrium, calcium, phosphorus, and magnesium were collected. Prosthesis type, material of plugging the location hole of femur, administration of TXA, HCA, and anticoagulant drug were also recorded.

\section{Estimation of blood loss}

Total blood loss was estimated with Gross equation [22]. The actual blood loss could be acquired by subtracting the autologous blood transfusion and the allogenetic blood transfusion. The specific calculation method for the Gross equation: total blood loss = patient blood volume $(\mathrm{PBV})^{2} \times($ preoperative Hct - post-operative Hct)/ (preoperative Hct + post-operative Hct). In which PBV = $\mathrm{k} 1 \times[\text { height }(\mathrm{m})]^{3}+\mathrm{k} 2 \times$ body weight $(\mathrm{kg})+\mathrm{k} 3$. For males, $\mathrm{k} 1=0.3669, \mathrm{k} 2=0.0329$, and $\mathrm{k} 3=0.6041$; for females, $\mathrm{k} 1=0.3561, \mathrm{k} 2=0.03308$, and $\mathrm{k} 3=0.1833$. The total blood losses of the first, third, and fifth days after the operation were calculated. In addition, the increased blood losses between the first day and third day after operation were calculated, which could be considered as hidden blood loss after operation.

\section{Transfusion management}

Both allogenic transfusion and autologous transfusion were employed during the operation and postoperatively, which was based on the condition of patients. The post-operative draining blood was collected for autologous transfusion that was performed $6 \mathrm{~h}$ after operation with an autologous negative pressure drainage device, ConstaVac TM CBC II (Stryker, USA). The allogenic transfusion triggers were based on the British guideline [23] and clinical judgment. On the one hand, the traditional view on transfusion triggers was $\mathrm{Hb}<70 \mathrm{~g} / \mathrm{L}$ and hematocrit $<25 \%$. $\mathrm{Hb}<$ $80 \mathrm{~g} / \mathrm{L}$ was a transfusion trigger for patients with cardiovascular and respiratory problems or patients aged $>65$ years. On the other hand, clinical manifestations presenting by that were considered as acute anemia, such as a drop in blood pressure $(<90 / 60 \mathrm{mmHg})$, dizziness, pale lips, weakness, and shortness of breath, were also regarded as transfusion trigger.

\section{Statistical analysis}

Twenty-two kinds of factors were divided into quantitative and quantitative variables. Multivariable stepwise linear regression was used to find out the impact factors of blood loss. In consideration of the peak of post-operative blood loss, the blood loss in the third day after TKA was chosen as the dependent variable. The continuous blood loss between the first day and third day after operation also attracted our attention. That was also set as a dependent variable.

Fifteen quantitative variables were included: BMI, PT, APTT, TT, Fbgc, preoperative $\mathrm{Hb}$, preoperative $\mathrm{HCT}$, ALB, kalium, natrium, calcium, phosphorus, magnesium, age, and operation time. Seven qualitative variables were included in the multiple linear regression analysis. For the gender, the male was set as " 1 " and female was " 0. " For the different prosthesis type, "CR" was set as " 0 " and "PS" was set as "1." For the utilization of drainage, "without drainage" was set as "0" and "with drainage" was set as "1." For the material of plugging the location hole of femurs, "nothing" was set as "0," "cement" was set as "1," and "bone" was set as "-1." For the use of tranexamic acid, four subgroups were set. "Not use" was set as "1", and the rest was a dummy variable. Same method 
was used for "topical application," "intravenous application," and "combined application." For the use of hemocoagulase agkistrodon, "not use" was set as "0" and "use" was set as "1." For the application of anticoagulation drugs, "LMWH" was set as "1" and "Rivaroxaban" was set as "0."

\section{Results}

\section{Estimation of blood loss and transfusion}

The total blood loss in the first, third, and fifth days after TKA and the increased blood loss volume were described in Table 3. In the third day after the operation, the average blood loss reached the biggest volume and it was $1346 \pm 671 \mathrm{~mL}$. Compared to the blood loss volume in the first day after operation, in an average, $465 \pm 358$ $\mathrm{mL}$ blood loss was found more in the third day. However, averagely $750 \pm 392 \mathrm{~mL}$ blood loss was found in the third day less than that in the fifth day after TKA.

More than half of the patients (51.55\%) have received transfusion within 3 days after operation, including allogenic transfusion, autologous transfusion, and both. The allogenic transfusion rate reached $35.09 \%$, and the average volume was $0.9 \mathrm{u}(0 \sim 6 \mathrm{u}) .31 .68 \%$ of the patients received autologous transfusion that reached $169.09 \mathrm{~mL}$ in average, of which 49 patients received allogenic transfusion as well. No complications associated with transfusion were found in the study.

\section{Multivariable stepwise linear regression analysis}

The result of the multivariable stepwise linear regression analysis showed that gender $(P<0.001)$, without TXA $(P<0.001)$, drainage $(P=0.019)$, and prosthetic type $(P<0.001)$ were positively correlated with total blood loss of TKA, but the rest of the potential risk factors presented a negative result. Male appeared to suffer more surgical blood loss than female. PS prosthesis might lead to more surgical blood loss than CR prosthesis. Tranexamic acid could effectively reduce total blood loss while drainage might increase bleeding. However, different strategies of using TXA showed no effect on blood loss. The regression model was shown in Fig. 1.

Another result showed that gender $(P<0.001)$ and different anticoagulation drugs $(P=0.009)$ were correlated with the hidden blood loss. Similarly, more blood loss was found in the male. Patients who received rivaroxaban suffered more post-operative bleeding. The regression model was shown in Fig. 2.

\section{Discussion}

In the present study, we found that total blood loss was $1346 \mathrm{~mL}$ in OA patients undergoing TKA. It was almost $30 \%$ of the total blood volume. Consistently, other scholars reported an approximate number. Sehat et al. found that the average blood loss of knee resurfacing arthroplasty was $1471 \mathrm{~mL}$ [6]. Digas et al. reported that the total blood loss was $1455 \mathrm{~mL}$ for patients with OA undergoing primary TKA. Despite rational use of TXA, the blood loss remained a large volume and it was 1044 $\mathrm{mL}$ [8]. Another study reported by Sizer et al. declared that the blood loss of the elderly ( $>75$ years old) after the primary knee replacement even reached $1741 \mathrm{~mL}$ [5].

High transfusion rate was present with the large blood loss eventually, which might influence the postoperative rehabilitation. Astonishingly, Stanworth and other scholars found that the allogeneic blood transfusion rate was as high as $21-70 \%$ for patients undergoing TKA $[24,25]$. More than half of the patients had received transfusion in our study, of which $68 \%$ of the patients needed an allogenic transfusion. Though no complication associated with transfusion was found in the study, the risk of associated complication was reported potentially increased, including extended hospital stays, infectious disease, immune response, and cardiopulmonary overload and reaction of hemolytic [24-26]. Effective steps should be launched to reduce the blood loss and transfusion. It is the primary job to find out the exact influential factors.

Multivariable stepwise linear regression analysis revealed that gender, TXA, drainage, and prosthetic type were correlated with total blood loss of TKA. But we found no correlation with age, BMI, operation time, electrolyte, and coagulation test indexes. Notably, gender difference could affect surgical blood loss including total blood loss and hidden blood loss, with greater amount in men compared with women. The result also received agreement from many scholars [11, 26, 27] who also proved that male had a high risk of suffering more blood loss than female in TKA.

Apart from gender, we also found that different prosthesis type and drainage played a role in influencing blood loss in TKA. The main source of bleeding might be from the venous sinus and the trimmed bone. In the authors' opinion, PS prosthesis with intercondylar bone osteotomy was possible to suffer more blood loss than $\mathrm{CR}$ prosthesis since more bone was cut. Mahringer et al. [28] and Scott et al. [29] announced the same result.

Table 3 Surgical blood loss

\begin{tabular}{|c|c|c|c|c|c|}
\hline & First day & Third day & Fifth day & First to third days & Third to fifth days \\
\hline & Mean \pm SD & Mean \pm SD & Mean \pm SD & Mean \pm SD & Mean \pm SD \\
\hline Volume (mL) & $880 \pm 560$ & $1346 \pm 671$ & $595 \pm 637$ & $465 \pm 358$ & $-750 \pm 392$ \\
\hline
\end{tabular}



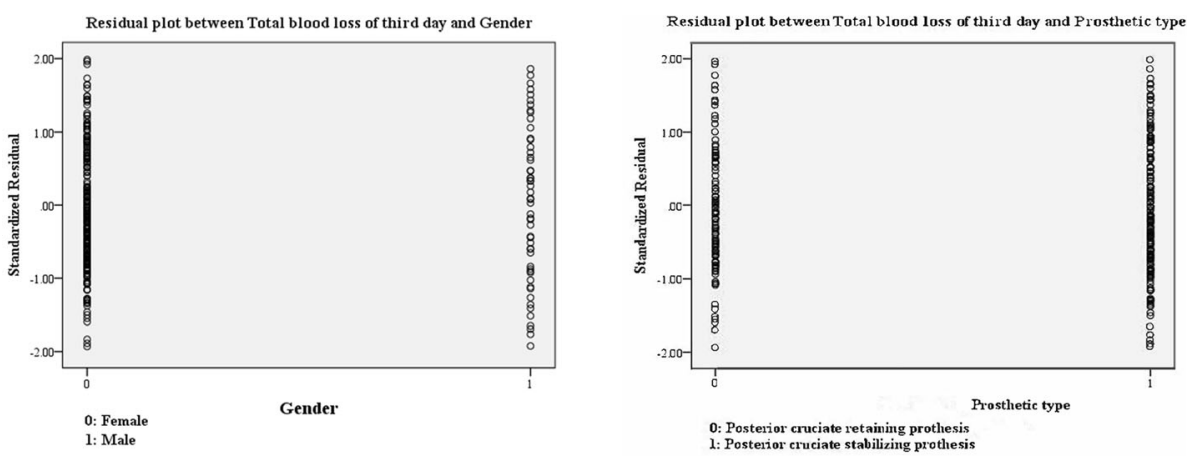

Residual plot between Total blood loss of third day and Tranexamic acid
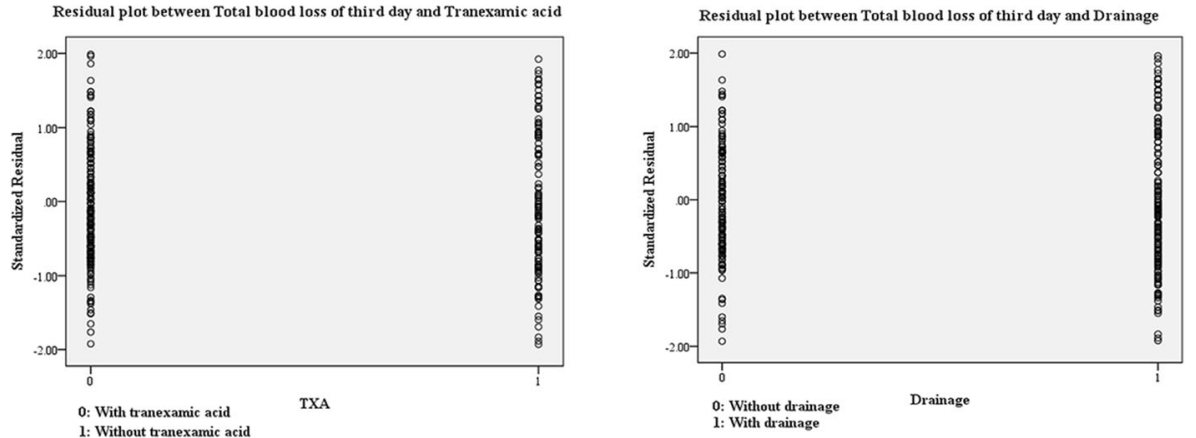

TBL=1328.329+Male*299.836+Without TXA*559.415+PS*179.529+Drainage*333.414

TBL: total blood loss, TXA: tranexamic acid, PS: posterior cruciate stabilizing prothesis

Fig. 1 Residual plots between total blood loss and each meaningful factor. The regression model well matches the data

The results could possibly be explained by the additional preparation of the femoral box PS TKA for the cam-post mechanism, which resulted in more femoral cancellous bone surface being exposed [28]. However, the materials of plugging the femur had an impact on total blood loss due to the continuous blood loss from venous sinuses of newly appearing cancellous bone. In addition, drainage might release the compression of hemorrhage and exudation, which could reduce the bleeding through oppressing the venous sinus and capillary. Parkers and Roberts indicated that drainage was not recommended for orthopedic surgeons, because no difference was found in the incidence of wound infection, hematoma, or dehiscence between with-drainage and without-drainage. But blood transfusion was required more frequently in those who received drains [30]. The more transfusion also reflected the more blood loss associated with drainage, which supported our results.

The balance between hemostasis and anticoagulation is always a challenge to orthopedic surgeons. With
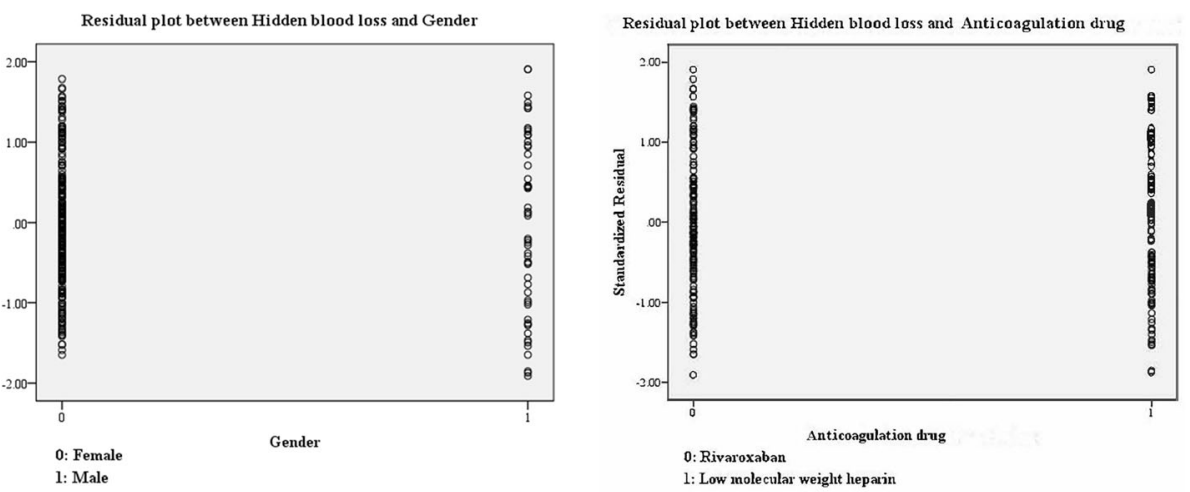

Hidden Blood loss=502.377+Male*210.227+Low Molecular Weight Heparin*(-105.235)

Fig. 2 Residual plots between hidden blood loss and each meaningful factor. The regression model well matches the data 
adequate strategy of using hemostasis and anticoagulation, it might reduce blood loss but not increase the risk of thrombus. The result showed that both TXA and anticoagulation drugs including LMWH and rivaroxaban might influence the blood loss.

Regarding the best method of applying TXA, it remains a controversy. Chareancholvanich and co-worker stated that an intravenous injection was the best method for rapidly increasing and maintaining the therapeutic concentration of TXA for patient undergoing TKA [31]. Digas et al. found that intra-articular administration of TXA seemed to be more effective in terms of reducing drained blood loss and transfusion frequency [8]. Another study reported by $\mathrm{Li}$ et al. proposed that the combined use of intravenous and topical TXA in patients with total knee arthroplasty was associated with significantly reduced total blood loss, transfusion requirements, post-operative hemoglobin decline, and length of stay compared to single application alone [32]. However, many scholars showed the agreement on our result. They discovered that topical TXA was equally effective compared with intravenous TXA in reducing blood loss and transfusion rate following TKA [33-35].

Therefore, we suggested that topical use of TXA might be the preferential option for patients undergoing TKA, because intravenous application might potentially result in higher risk of complication occurrence than topical application. TXA is an inhibitor of fibrinolysis that acts by blocking the lysine-binding site of plasminogen to fibrin and prevents the degradation of fibrin. Patients utilizing TXA were risky to suffer phlebothrombosis as they have to stay in bed after TKA for a long time, which should raise concern. Wu et al. found that the intravenous use of TXA presents higher deep venous thrombosis (DVT) than the control group, and the incidence reached $6.3 \%$ while it was $3.8 \%$ with topical use [36]. In addition, Aydin and co-worker proposed other benefits of intra-articular injection of TXA apart from reducing blood loss, which suggested administration of intra-articular TXA significantly shortening the post-operative length of hospital stay and reducing the total hospital costs [37].

The continuous blood loss after operation, or named hidden blood loss, is also a problem that cannot be neglected. The hidden blood loss reached $465 \mathrm{~mL}$ in our study. Some scholars suggested that hidden blood loss might be correlated with hemolysis, blood infiltration into tissue compartments, and the use of anticoagulant drugs $[38,39]$. To prevent DVT, anticoagulant drugs were irreplaceable for knee replacement. Mainly LMWH and rivaroxaban were the preferred one. Rivaroxaban is an oral anticoagulant that directly inhibits the activity of factor Xa. Carrother et al. found that rivaroxaban can significantly reduce the incidence of DVT [40]. Fuji et al. further proved that the Xa inhibitors have superior efficacy compared with enoxaparin for the prevention of venous thromboembolism in patients following TKA with comparable bleeding [41, 42]. However, Li et al. presented the different conclusion that rivaroxaban did not increase the risk of hidden blood loss but LMWH increased the risk of dominant blood loss [15]. In contrast, we found that LMWH might result in less hidden blood loss while rivaroxaban potentially increases the bleeding. Similarly, Wang et al. [43] and Zou et al. [44] showed the same results.

Different from rivaroxaban that inhibits clotting factor $\mathrm{Xa}$, the major anticoagulant effect of heparin is through its interaction with antithrombin-III (AT-III). This interaction markedly accelerates the ability of AT-III to inactivate the coagulation enzymes thrombin, factor Xa, and factor IXa. Moreover, LMWH, the fragments of standard commercial grade heparin produced by either chemical or enzymatic depolymerization, have reduced ability to catalyze the inactivation of thrombin relative to their ability to inhibit factor Xa because the inactivation of thrombin by heparin is critically dependent on molecular size [45]. Researches of platelet function [46] and vascular permeability [47] have provided plausible explanations for the reduced experimental bleeding observed with LMWH. Higher evidence quality research, a random control cohort study related to the influence of rivaroxaban and LMWH on hidden blood loss, needs to further carry out.

\section{Conclusions}

The total blood loss reached $1346 \pm 671 \mathrm{~mL}$ in the third day after TKA. The potential influential factors of total blood loss included gender, TXA, prosthesis type, and drainage. Male was considered to suffer more surgical blood loss than female. Perioperative blood management should be enhanced in male patients. Posterior cruciate retaining (CR) prosthesis might be superior in reducing total blood loss of TKA. Drainage was not recommended due to the risk of increasing bleeding. Tranexamic acid was proven to effectively reduce total blood loss, and the topical use was preferred. The hidden blood loss was $465 \pm 358 \mathrm{~mL}$, and its impact factors mainly included gender and the different use of anticoagulation. As for the selection to prevent DVT between the low molecular heparin and rivaroxaban, the former was recommended since it might lead to less hidden blood loss.

\section{Abbreviations}

ALB: Albumin; APTT: Activated partial thromboplastin time; AT-III: AntithrombinIII; BMI: Body mass index; CPM: Continuous passive motion exercise device; CR: Posterior cruciate retaining; CRP: C-reactive protein; DVT: Deep venous thrombosis; Fbgc: Fibrinogen concentration; Hb: Hemoglobin; HCA: Hemocoagulase agkistrodon injection; Hct: Hematocrit; LMWH: Low molecular weight heparin; OA: Osteoarthritis; Plt: Platelet; PS: Posterior cruciate stabilizing; PT: Prothrombin time; PT\%: Prothrombin activity; PT- 
INR: Prothrombin time international ratio; TKA: Total knee arthroplasty; TT: Thrombin time; TXA: Tranexamic acid injection

\section{Acknowledgements}

The authors would like to sincerely appreciate Dr. Candy Kuang's selfless help for revising the spelling and grammar errors of the manuscript.

\section{Funding}

This research received no specific grant from any funding agency in the public, commercial or not-for-profit sectors.

\section{Availability of data and materials}

The datasets used and/or analyzed during the current study are available from the corresponding author on reasonable request.

\section{Authors' contributions}

$J X, Y H$, and QL contributed to the conception and design of the study. YH was a major contributor for drafting the manuscript. QL, BGW, and XSZ contributed to the acquisition of the data. QL, BGW, XSZ, and TTT contributed to the analysis and interpretation of the data. JX and YH contributed to the critical revision for important intellectual content. QL, BGW, XSZ, TTT, and ZJS make important revisions. TTT was responsible for the language modifying. JX, YH, QL, BGW, SXZ, TTT, and ZJS contributed to the final approval of the version to be submitted. JX and YH were responsible for the overall content as guarantors. All authors read and approved the final manuscript.

\section{Ethics approval and consent to participate}

The study has gotten approval from Medical Ethics Committee of Nanfang hospital. Consent to participate is not applicable for this retrospective study.

\section{Consent for publication}

This section is not applicable for our study.

\section{Competing interests}

The authors declare that they have no competing interests.

\section{Publisher's Note}

Springer Nature remains neutral with regard to jurisdictional claims in published maps and institutional affiliations.

\section{Author details}

'Department of Orthopaedic Surgery, Nanfang Hospital, Southern Medical University, Guangzhou 510515, Guangdong Province, China. ${ }^{2}$ Department of Orthopaedic Surgery, Chinese Traditional Medicine Hospital of Huaihua City, Huaihua 418000, Hunan Province, China. ${ }^{3}$ Department of Orthopaedic Surgery, Inner Mongolia People's Hospital, Hohhot 100017, Inner Mongolia, China. ${ }^{4}$ Department of Orthopedic Surgery, The Third People's Hospital of Dongguan City, Dongguan 523326, Guangdong Province, China. ${ }^{5}$ Southern Medical University, Guangzhou 510515, Guangdong Province, China.

Received: 23 July 2018 Accepted: 11 December 2018

Published online: 22 December 2018

\section{References}

1. Busija $L$, Bridgett $L$, Williams SR, Osborne RH, Buchbinder R, March $L$, et al. Osteoarthritis. Best Pract Res Clin Rheumatol. 2010;24(6):757-68.

2. Insall JN, Dorr LD, Scott RD, Scott WN. Rationale of the Knee Society clinical rating system. Clin Orthop Relat Res. 1989;248:13-4.

3. Font-Rodriguez DE, Scuderi GR, Insall JN. Survivorship of cemented total knee arthroplasty. Clin Orthop Relat Res. 1997;345:79-86.

4. Ranawat CS, Padgett DE, Ohashi Y. Total knee arthroplasty for patients younger than 55 years. Clin Orthop Relat Res. 1989;248:27-33.

5. Sizer SC, Cherian JJ, Elmallah RDK, Pierce TP, Beaver WB, Mont MA. Predicting blood loss in total knee and hip arthroplasty. Orthop Clin N Am. 2015;46(4):445-59.

6. Sehat KR, Evans R, Newman JH. How much blood is really lost in total knee arthroplasty?. Correct blood loss management should take hidden loss into account. Knee. 2000;7(3):151-5.

7. Lošták J, Gallo J, Mlčůchová D. Multivariate analysis of blood loss during primary total hip or knee arthroplasty. Acta Chir Orthop Traumatol Cechoslov. 2013;80(3):219.
8. Digas G, Koutsogiannis I, Meletiadis G, Antonopoulou E, Karamoulas V, Bikos C. Intra-articular injection of tranexamic acid reduce blood loss in cemented total knee arthroplasty. Eur J Orthop Surg Traumatol. 2015;25(7):1181-8.

9. Lu Q, Peng H, Zhou G-J, Yin D. Perioperative blood management strategies for total knee arthroplasty. Orthop Surg. 2018;10(1):8-16.

10. Klein HG. How safe is blood, really? Biologicals. 2010;38(1):100-4.

11. Cushner FD, Friedman RJ. Blood loss in total knee arthroplasty. Clin Orthop Relat Res. 1991:(269):98-101.

12. Mesa-Ramos F, Mesa-Ramos M, Maquieira-Canosa C, Carpintero P. Predictors for blood transfusion following total knee arthroplasty: a prospective randomised study. Acta Orthop Belg. 2008;74(1):83-9.

13. Sabatini L, Atzori F, Revello S, Scotti L, Debiasi F. Intravenous use of tranexamic acid reduces postoperative blood loss in total knee arthroplasty. Arch Orthop Trauma Surg. 2014;134(11):1609-14.

14. Shimizu M, Kubota R, Nasu M, Usami J, Kataoka H, Nagaoka H, et al. The influence of tourniquet during total knee arthroplasty on perioperative blood loss and postoperative complications. Masui. 2016;65(2):131-5.

15. Li J, Jing J, Zhou Y, Yao Y, Zhan J. Comparison of rivaroxaban and enoxaparin on blood loss after total knee arthroplasty. Zhongguo Xiu Fu Chong Jian Wai Ke Za Zhi. 2014;28(1):26-9.

16. Horstmann W, Kuipers B, Ohanis D, Slappendel R, Kollen B, Verheyen C. Autologous re-transfusion drain compared with no drain in total knee arthroplasty: a randomised controlled trial. Blood Transfus. 2014; 12(Suppl 1):s176-81.

17. Zhang Y, Li ZJ, Zheng YF, Feng SQ, Li H. Delayed drainage versus autotransfusion drainage and routine drainage after total knee arthroplasty: a comparative study. J Orthop Surg Res. 2013;8:39.

18. Liao C-D, Huang Y-C, Lin L-F, Chiu Y-S, Tsai J-C, Chen C-L, et al. Continuous passive motion and its effects on knee flexion after total knee arthroplasty in patients with knee osteoarthritis. Knee Surg Sports Traumatol Arthrosc. 2016;24(8):2578-86.

19. Pope RO, Corcoran S, McCaul K, Howie DW. Continuous passive motion after primary total knee arthroplasty. Does it offer any benefits? J Bone Joint Surg Br. 1997;79(6):914-7.

20. Goletz TH, Henry JH. Continuous passive motion after total knee arthroplasty. South Med J. 1986;79(9):1116-20.

21. Bible JE, Simpson AK, Biswas D, Pelker RR, Grauer JN. Actual knee motion during continuous passive motion protocols is less than expected. Clin Orthop Relat Res. 2009;467(10):2656-61.

22. Gross JB. Estimating allowable blood loss: corrected for dilution. Anesthesiology. 1983;58(3):277-80.

23. Murphy M, Wallington $T$, Kelsey $P$, Boulton F, Bruce $M$, Cohen $H$, et al. Guidelines for the clinical use of red cell transfusions. Br J Haematol. 2001; 113(1):24.

24. Bierbaum BE, Callaghan JJ, Galante JO, Rubash HE, Tooms RE, Welch RB. An analysis of blood management in patients having a total hip or knee arthroplasty. J Bone Joint Surg Am. 1999;81(1):2-10.

25. Frisch NB, Wessell NM, Charters MA, Yu S, Jeffries JJ, Silverton CD. Predictors and complications of blood transfusion in total hip and knee arthroplasty. J Arthroplast. 2014;29(9 Suppl):189-92.

26. Guerin S, Collins C, Kapoor H, McClean I, Collins D. Blood transfusion requirement prediction in patients undergoing primary total hip and knee arthroplasty. Transfus Med. 2007;17(1):37-43.

27. Prasad N, Padmanabhan V, Mullaji A. Blood loss in total knee arthroplasty: an analysis of risk factors. Natl Med Front China. 2007;31(1):39-44.

28. Mähringerkunz A, Efe T, Fuchswinkelmann S, Schüttler KF, Paletta JR, Heyse TJ. Bleeding in TKA: posterior stabilized vs. cruciate retaining. Arch Orthop Trauma Surg. 2015;135(6):867-70.

29. Scott DF, Smith RR. A prospective, randomized comparison of posterior stabilized versus cruciate-substituting total knee arthroplasty: a preliminary report with minimum 2-year results. J Arthroplast. 2014; 29(9):179-81.

30. Parker MJ, Livingstone $\mathrm{V}$, Clifton R, McKee A. Closed suction surgical wound drainage after orthopaedic surgery. Cochrane Database Syst Rev. $2001 ;(4): C d 001825$

31. Chareancholvanich $K$, Siriwattanasakul P, Narkbunnam R, Pornrattanamaneewong C. Temporary clamping of drain combined with tranexamic acid reduce blood loss after total knee arthroplasty: a prospective randomized controlled trial. BMC Musculoskelet Disord. 2012;13:124.

32. Li JF, Li H, Zhao H, Wang J, Liu S, Song Y, et al. Combined use of intravenous and topical versus intravenous tranexamic acid in primary total 
knee and hip arthroplasty: a meta-analysis of randomised controlled trials. J Orthop Surg Res. 2017;12(1):22.

33. May JH, Rieser GR, Williams CG, Markert RJ, Bauman RD, Lawless MW. The assessment of blood loss during total knee arthroplasty when comparing intravenous vs intracapsular administration of tranexamic acid. J Arthroplast. 2016;31(11):2452-7.

34. Chen TP, Chen YM, Jiao JB, Wang YF, Qian LG, Guo Z, et al. Comparison of the effectiveness and safety of topical versus intravenous tranexamic acid in primary total knee arthroplasty: a meta-analysis of randomized controlled trials. J Orthop Surg Res. 2017;12(1):11.

35. Nawabi DH. Topical tranexamic acid was noninferior to intravenous tranexamic acid in controlling blood loss during total knee arthroplasty. J Bone Joint Surg. 2015;97(4):343.

36. Wu Q, Zhang HA, Liu SL, Meng T, Zhou X, Wang P. Is tranexamic acid clinically effective and safe to prevent blood loss in total knee arthroplasty? A meta-analysis of 34 randomized controlled trials. Eur J Orthop Surg Traumatol. 2015;25(3):525-41.

37. Aydin BK, Durgut F, Erkocak OF, Acar MA. Other benefits of intra-articular injection of tranexamic acid in primary total knee arthroplasty apart from reducing blood transfusion rates. Eklem Hastalik Cerrahisi. 2017;28(1):25-9.

38. Erskine JG, Fraser C, Simpson R, Protheroe K, Walker ID. Blood loss with knee joint replacement. J R Coll Surg Edinb. 1981;26(5):295.

39. Faris PM, Ritter MA, Keating EM, Valeri CR. Unwashed filtered shed blood collected after knee and hip arthroplasties. A source of autologous red blood cells. J Bone Joint Surg Am. 1991;73(8):1169-78.

40. Carrothers AD, Rodriguez-Elizalde SR, Rogers BA, Razmjou H, Gollish JD, Murnaghan JJ. Patient-reported compliance with thromboprophylaxis using an oral factor Xa inhibitor (rivaroxaban) following total hip and total knee arthroplasty. J Arthroplast. 2014;29(7):1463-7.

41. Fuji T, Fujita S, Kawai Y, Nakamura M, Kimura T, Kiuchi Y, et al. Safety and efficacy of edoxaban in patients undergoing hip fracture surgery. Thromb Res. 2014;133(6):1016-22.

42. Fuji T, Wang C-J, Fujita S, Kawai Y, Nakamura M, Kimura T, et al. Safety and efficacy of edoxaban, an oral factor Xa inhibitor, versus enoxaparin for thromboprophylaxis after total knee arthroplasty: the STARS E-3 trial. Thromb Res. 2014;134(6):1198-204.

43. Wang G, Zhang $Y$, Zhao X, Zhang Y, Wang L, Kong Y. Impact of ivaroxaban on hidden blood loss and blood transfusion rate after primary total knee arthroplasty. Zhongguo Xiu Fu Chong Jian Wai Ke Za Zhi. 2012;26(11):1306-9.

44. Zou Y, Tian S, Wang Y, Sun K. Administering aspirin, rivaroxaban and lowmolecular-weight heparin to prevent deep venous thrombosis after total knee arthroplasty. Blood Coagul Fibrinolysis. 2014;25(7):660.

45. Vitoux JF. Low molecular weight heparin. Rev Med Interne. 1988;9(3):235-7.

46. Salzman EW, Rosenberg RD, Smith MH, Lindon JN, Favreau L. Effect of heparin and heparin fractions on platelet aggregation. J Clin Investig. 1980;65(1):64-73.

47. Fernandez F, Ryn JV, Ofosu FA, Hirsh J, Buchanan MR. The hemorrhagic and antithrombotic effect of dermatan sulfate. Br J Haematol. 1986;64(2):309-17.

Ready to submit your research? Choose BMC and benefit from:

- fast, convenient online submission

- thorough peer review by experienced researchers in your field

- rapid publication on acceptance

- support for research data, including large and complex data types

- gold Open Access which fosters wider collaboration and increased citations

- maximum visibility for your research: over $100 \mathrm{M}$ website views per year

At BMC, research is always in progress.

Learn more biomedcentral.com/submissions 